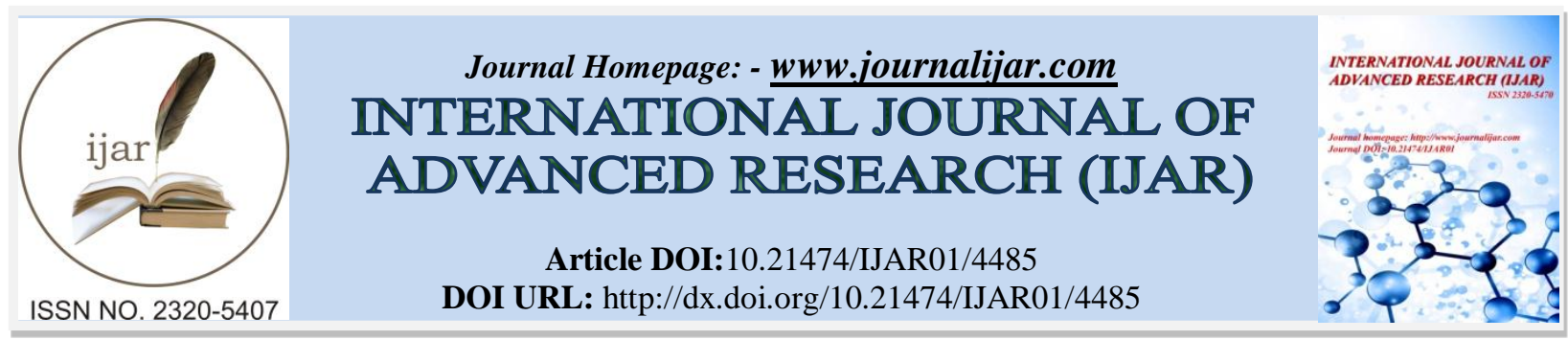

RESEARCH ARTICLE

\title{
RELATIONSHIP BETWEEN PAIN, DISABILITY AND QUALITY OF LIFE IN PATIENTS WITH LOW BACK PAIN.
}

\author{
Daljit Singh $^{1}$, Akshav Aggarwal ${ }^{2}$, Sandeep Kumar ${ }^{3}$ and Smati Sambyal ${ }^{4}$. \\ 1. BPT Final year, University College of Physiotherapy, Faridkot. \\ 2. BPT, University College of Physiotherapy, Faridkot. \\ 3. Lecturer, University College of Physiotherapy, Faridkot.
}

\section{Manuscript Info}

Manuscript History

Received: 14 April 2017

Final Accepted: 16 May 2017

Published: June 2017

Key words:-

Low back pain, disability, quality of life

\section{Abstract}

Introduction: Chronic low back pain is considered as public health problem of clinical, social and economic importance, which affects the population without distinction ${ }^{(1)}$. It is a highly prevalent and costly musculoskeletal problem in economically advanced societies nowadays. It can cause long-term disability, absenteeism from work and frequent health service use ${ }^{(2)}$ and therefore, requires effective management. This study investigated the effect of pain on Disability and Quality of Life in patients with chronic low back pain.

Methodology: Total of 30 patients, with 15 males and 15 females, with chronic low back pain were included in the study whereas the patients having any history of prior surgery within last three months or received any medical and physiotherapeutic intervention for the management of low back pain were excluded from the study. All the participants were then assessed for low back pain with Visual Analogue Scale (VAS), back disability with Roland-Morris Low back pain disability questionnaire and Quality of Life with SF-36 Questionnaire.

Results: The highest correlation was found between disability and quality of life $(\mathrm{r}-\mathrm{value}=.839)$ and lowest correlation was found between low back pain and quality of life(r-value $=.788)$.

Conclusion: It has been concluded from the study that low back pain, disability and quality of life were significantly correlated to each other. Therefore, decrease in low back pain improves the quality of life and lessen the disability of the patients

Copy Right, IJAR, 2017,. All rights reserved.

\section{Introduction:-}

Low back pain (LBP) is fifth most common reason for all physician visits and is second most common symptomatic reason (upper respiratory symptoms are first) ${ }^{(3)}$. The incidence of LBP is highest in the 3rd decade of life \& its prevalence increases with age until 60-65 age groups and then gradually declines ${ }^{(4)}$. It arises from any one of number of anatomical structures including bones, intervertebral discs, joints, ligaments, muscles, neural structures and blood vessels ${ }^{(5)}$. Chronic low back pain is a highly prevalent and costly musculoskeletal problem in economically advanced societies nowadays. It can cause long-term disability, absenteeism from work and frequent health service use ${ }^{(2)}$. Therefore, low back pain is considered a public health problem of clinical, social and 
economic importance, which affects the population without distinction ${ }^{(1)}$ and requires effective management. Adequate management of pain experiences is only possible if this subjective phenomenon and directly related factors are assessed and measured. So, this study was planned to investigate relationship between low back pain, quality of life and disability in patients with low back pain.

\section{Methodology:-}

Total of 30 patients, with low back pain, were selected. Out of which 15 were males and 15 were females. Patients with medical diagnosis of specific or non-specific chronic low back pain over 18 years of age were included in the study and thepatients having any type of Cognitive disorders, receiving any medical and physiotherapeutic intervention for low back pain, lack of understanding or any kind of surgery within the last three months were excluded from the study. After that all the patients were assessed for low back pain, disability and quality of life with Visual Analogue Scale (VAS), Roland-Morris Low back pain disability questionnaire and SF-36 Questionnaire respectively

Statistical Analysis:- The statistical analysis of present study was done by using SPSS-16, which shows the significant correlation between pain, disability and quality of life.

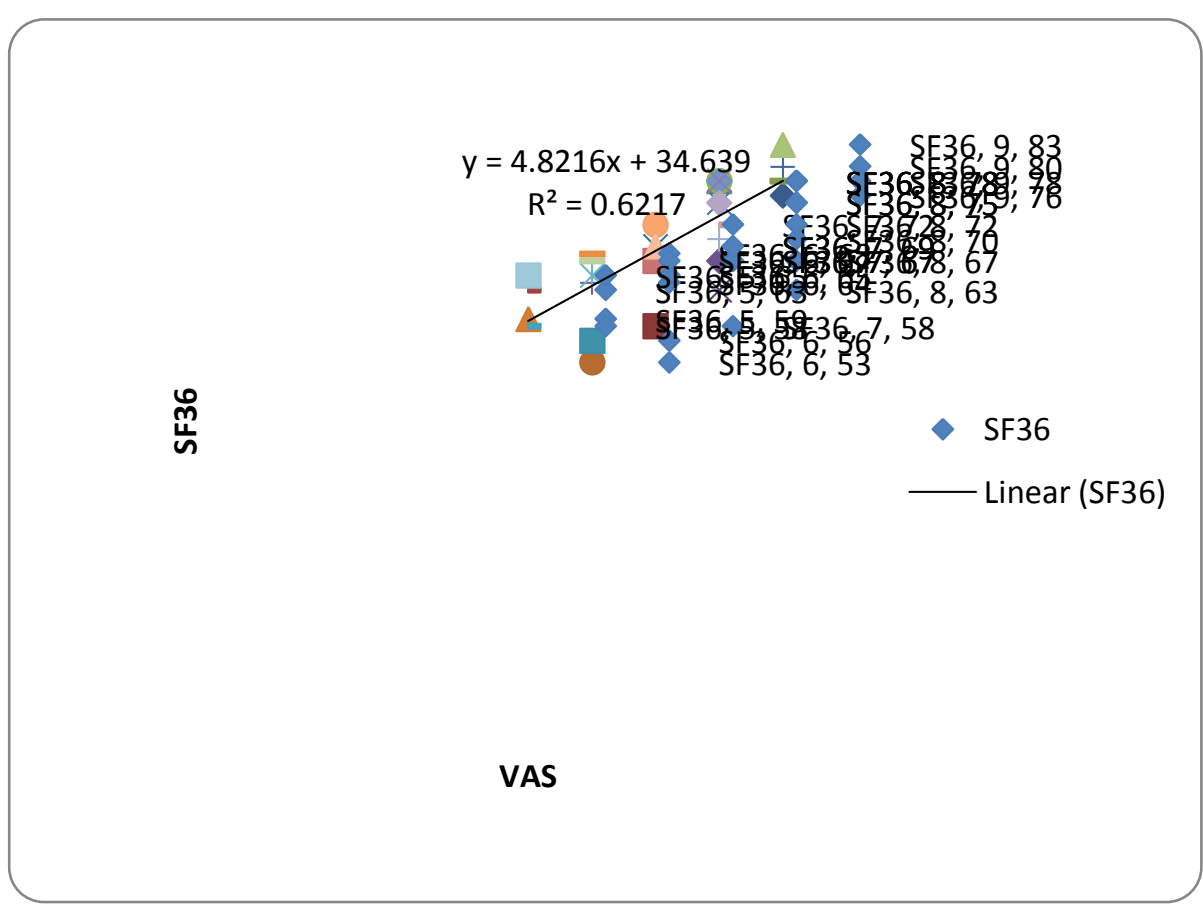

Fig 1.1:- Graphical display of Correlation between low back pain and quality of life in patients suffering from low back pain. 


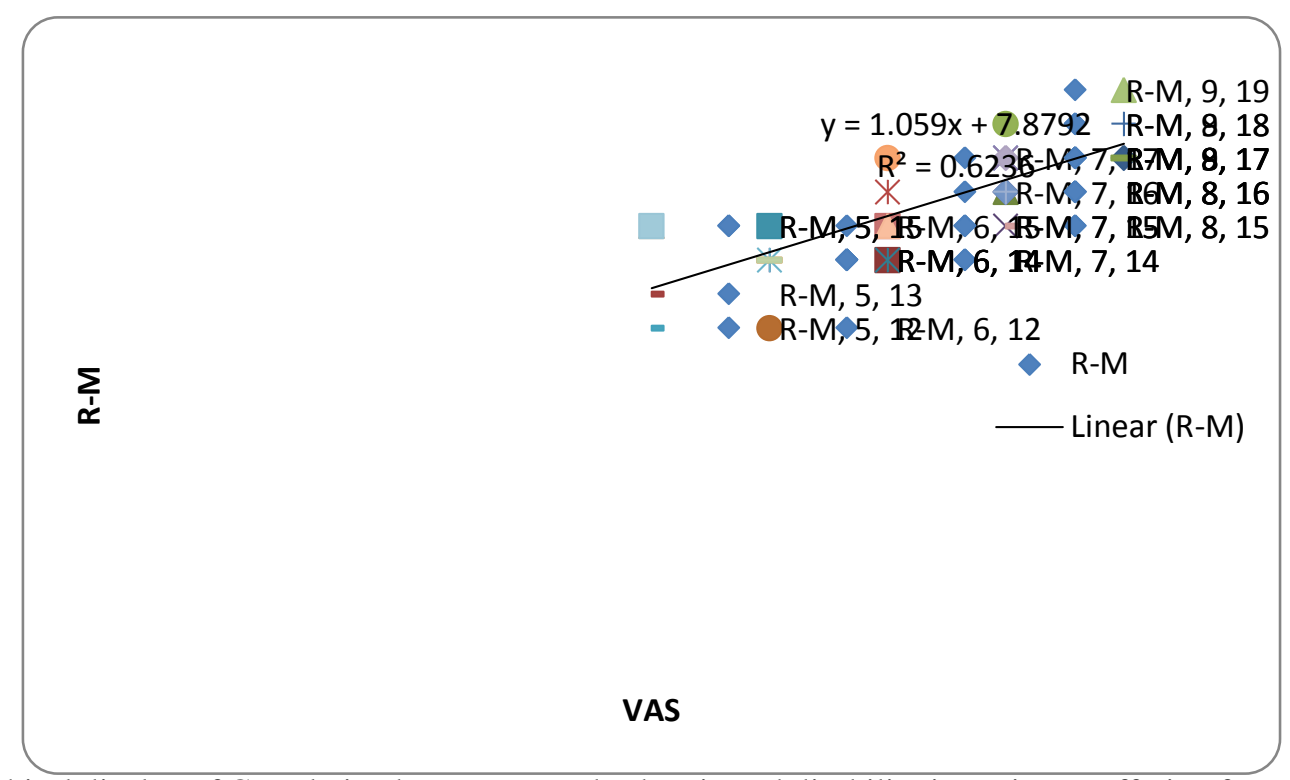

Fig 1.2:- Graphical display of Correlation between Low back pain and disability in patients suffering from low back pain.

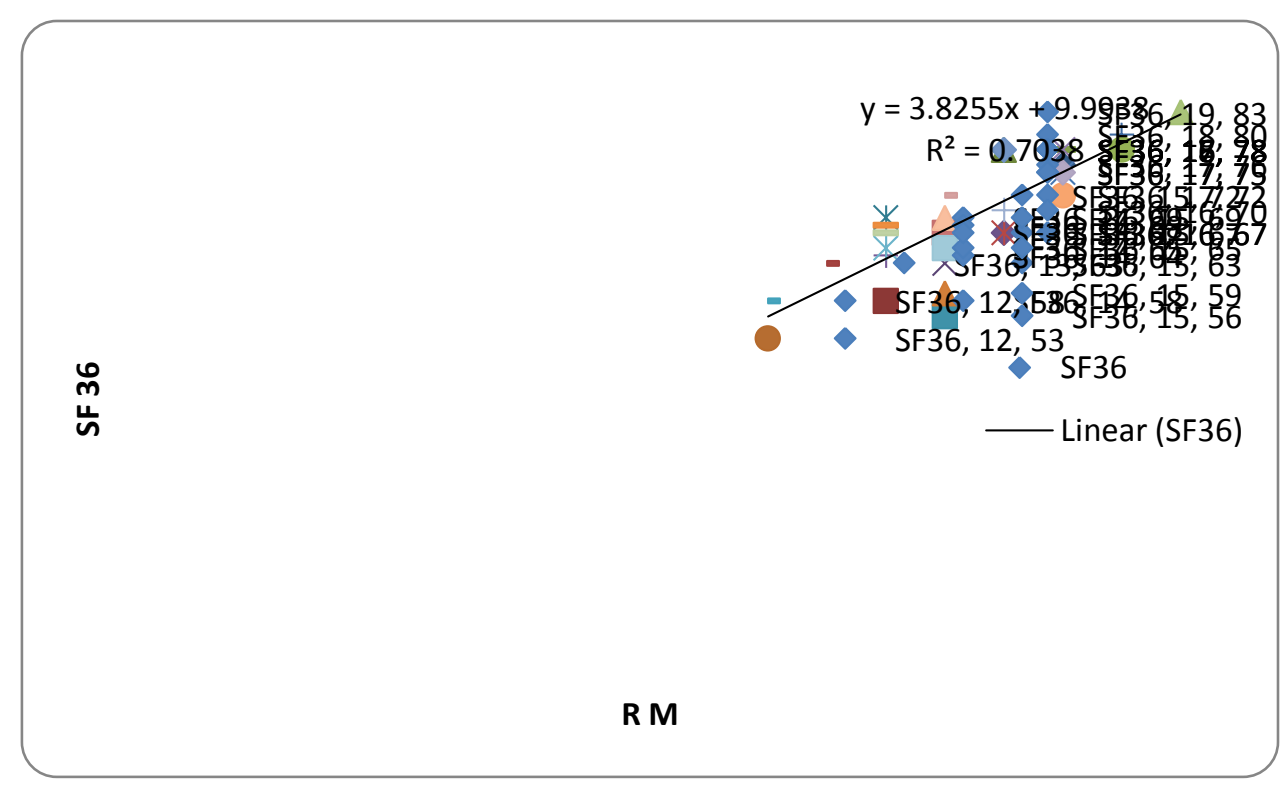

Flig, 1.3:- Graphical display of correlation between disability and quality of life in patients suffering from low back pain

\section{Discussion:-}

In this study, the perceived pain of chronic low back pain patients was assessed and compared with quality of life and physical disability levels. This permits knowledge on the relations between the attributes under analysis, highlighting how important it is to appropriately assess patients in pain and to take into account all attributes related to this phenomenon. The mean disability level observed in this sample with the help of the Roland-Morris questionnaire was 14.4 points, which represents severe disability ${ }^{(6)}$. The degree of disability found in this study is underlined, showing the extent to which chronic low back pain patients cannot perform daily activities normally. The higher pain measured in the last week revealed a mean score of 8.0 points. In another study, it was observed that, when asked about this parameter, $42 \%$ of the interviewees demonstrated strong low back pain in the last week, scored between seven and ten, on a scale from zero to ten ${ }^{(7)}$. The most affected QoL (Quality of Life) domain found 
in this study was the physical, in accordance with other studies ${ }^{(8)}$. In this study, a weak association was found between pain intensity and disability and QoL, indicating that pain intensity is weakly related to the degree of disability and QoL. This relation needs to be better understood in future research, with a view to furthering knowledge about what factors are more strongly associated with disability. A strong association was observed between disability and the physical domain of QoL, in accordance with studies in Slovenia ${ }^{(9)}$ and the Netherlands

(10). Health professionals need to focus on an active search for depression and anxiety signs and for better pain management in chronic low back pain patients, particularly in case of somatic comorbidities. This can lead to an important reduction in disability levels and improve quality of life, as expected for the appropriate management of these patients ${ }^{(9)}$. Study limitations include the lack of non-probabilistic sampling and of a control group for comparison.

\section{Conclusion:-}

It has been found that, there is highest correlation between disability and quality of life(r value $=.839)$ and lowest correlation between pain and quality of life(r value $=.788)$ which shows that with the increase in disability there is an adverse effect on quality of life. So, all the three parameters should be considered equally while treating the patients suffering from low back pain.

\section{Bibliography:-}

1. Manchikanti L. Epidemiology of low back pain. Pain Physician. 2000;3(2):167-192.

2. Gore M, Sadosky A, Stacey BR, Tai KS, Leslie D. The burden of chronic low back pain: clinical comorbidities, treatment patterns and health care costs in usual care settings. Spine ( Phila Pa 1976). 2012;37(11):E668-77.

3. Hart LG, Deyo RA, Cherkin DC. Physician office visits for low back pain. Frequency, clinical evaluation, and treatment patterns from a U.S. national survey.Spine. 1995;20:11-9.

4. ShyamalKoley, Severity of disability in elderly patients with low back pain in Amritsar Punjab. Anthropologist. 2008;10(4):265-268

5. D. Hoya, P. Brooks, The Epidemiology of low back pain. Best Practice \& Research Clinical Rheumatology 2010;24:769-781.

6. Monteiro J, Faisca L, Nunes O, Hipolito J. Questionário de incapacidade de Roland Morris. Adaptação e validaçãoparaosdoentes de línguaportuguesa com lombalgia.Acta Med Port. 2010;23(5):761-6.

7. Sherman KJ, Cherkin DC, Connelly MT, Erro J, Savetsky JB, Davis RB, et al. Complementary and alternative medical therapies for chronic low back pain

8. Wallace AS, Freburger JK, Darter JD, Jackman AM, Carey TS. Comfortably numb? Exploring satisfaction with chronic back pain visits. Spine J.2009;9(9):721-8

9. Klemenc-Ketis Z. Predictors of health-related quality of life and disability in patients with chronic non-specific low back pain. ZdravVestn. 2011;80(5):379-85.

10. Kindermans HP, Huijnen IP, Goossens ME, Roelofs J, Verbunt JA, Vlaeyen JW. "Being" in pain: the role of self-discrepancies in the emotional experience and activity patterns of patients with low back pain.Pain. 2011;152(2):403-9 